\title{
Catalytic Amplification of Electrochemical Signal in Homogeneous Solution Using an Entropy-driven DNA Circuit
}

\author{
Yusuke Kitamura, ${ }^{\dagger}$ Keisuke Yoshimura, Ryo Kuramoto, Yousuke Katsuda, and Toshihiro Ihara ${ }^{\dagger}$ \\ Division of Materials Science, Faculty of Advanced Science and Technology, Kumamoto University, \\ 2-39-1 Kurokami, Chuo, Kumamoto 860-8555, Japan
}

\begin{abstract}
The electrochemical signal from ferrocene on a DNA probe was successfully modulated in a homogeneous solution by the template-directed formation and dissociation of an inclusion complex with $\beta$-cyclodextrin on another probe. The electrochemical response was amplified by combining with a DNA circuit, in which the target DNA served as a catalyst. This system did not require any modification of a complementary DNA with the ferrocene-modified probe on the electrode surface to separate the bound/free probe for the detection of $200 \mathrm{nM}$ target DNA.
\end{abstract}

Keywords Nucleic acids, electrochemical biosensor, inclusion complex, ferrocene, cyclodextrin, homogeneous assay, DNA circuit, signal amplification

(Received October 11, 2020; Accepted October 30, 2020; Advance Publication Released Online by J-STAGE November 6, 2020)

\section{Introduction}

Nucleic acids are widely recognized as promising materials for fabricating a variety of nanodevices by self-assembly. These molecular nanodevices can execute dynamic functions encoded in sequences of the constituent DNAs/RNAs through autonomous repeating strand-exchange reactions. The simple rule of Watson-Crick base pairing and the general knowledge of thermodynamics and kinetics of hybridization enable the design of molecular nanodevices consisting of several orthogonal hybridization cascades. ${ }^{1-6}$ In addition, especially for DNA, the ease of preparation by enzymatic and chemical synthesis, and of modification, enable the construction of a variety of sophisticated sensing systems for various biomolecules. Recently, a number of research groups have proposed unique molecular systems that involve an autonomous repeating strand exchange of DNA, e.g., hybridization chain reactions, ${ }^{7}$ catalyzed hairpin assembly, ${ }^{8}$ and entropy-driven catalytic strand exchange, which are referred to as DNA circuits. ${ }^{9}$ These circuits have attracted much attention because of their potential use as robust molecular systems that can transduce specific interactions of interest into amplified signals. ${ }^{10-20}$

For several years, we have been engaged in the construction of unique nucleic acid detection systems based on cooperative interactions between split probes on targets. The formation of luminous metal complexes $^{21}$ and inclusion complexes, ${ }^{22}$ photochemical reactions, ${ }^{23}$ and allosteric assembly of DNA conjugate $^{24}$ have been used to generate specific signals. In a series of studies, we found that $\beta$-cyclodextrin $(\beta \mathrm{CyD})$ modified on a DNA end almost completely suppressed the electrochemical signal from ferrocene $(\mathrm{Fc}){ }^{22 \mathrm{a}, 22 \mathrm{~b}} \beta \mathrm{CyD}$ and $\mathrm{Fc}$ tethered to the

$\dagger$ To whom correspondence should be addressed.

E-mail: ykita@kumamoto-u.ac.jp (Y.K.); toshi@ chem.kumamoto-u. ac.jp (T. I.) ends of different DNAs form a tight inclusion complex on the DNA scaffold (single-stranded target). The $\mathrm{Fc}$ in the $\beta \mathrm{CyD}$ cavity is shielded from the bulk solution, which suppress the electron transfer efficiency with the electrode. In this case, $\beta \mathrm{CyD}$ is regarded as being a good quencher for electrochemical signals, similar to the azo-quenchers used in conventional molecular beacons based on fluorescence resonance energy transfer. This binary molecular system consisting of $\beta \mathrm{CyD}$ and $\mathrm{Fc}$ has promising potential applications and will enable electrochemical signal generation in homogeneous solutions.

Here, we investigated the design of a DNA circuit for electrochemical signal generation and amplification by using a target-triggered strand-exchange reaction of a tandem ternary duplex consisting of two DNA conjugates, i.e., $\beta \mathbf{C y D}-\mathbf{D N A}(\mathbf{Q})$ and Fc-DNA (E), and their complementary strand, which is referred to as the platform $(\mathbf{P})$. We used a combination of electrochemical signal generation based on dissociation of the inclusion complex between $\mathrm{Fc}$ and $\beta \mathrm{CyD}$ in a homogeneous solution and an entropy-driven DNA circuit to construct a turnon-type molecular system for electrochemical signal amplification (Fig. 1(a)).

\section{Experimental}

Probe design

Among several DNA circuits, we chose an entropy-driven DNA circuit for electrochemical signal amplification. Entropydriven DNA circuit provides fast kinetics and consists of modular DNA components, making it easier to modify their toehold domain for the detection of several targets. The amplification pathway is shown in Fig. 1. In the initial state, a $\beta \mathrm{CyD} \supset \mathrm{Fc}$ inclusion complex is formed on an $\mathbf{E} / \mathbf{P} / \mathbf{Q}$ tandem ternary duplex, in which the electrochemical signal of $\mathrm{Fc}$ is expected to be quenched. The target DNA (T) added to the system displaces $\mathbf{Q}$ by strand exchange from the toehold, 5*, to 
(a)

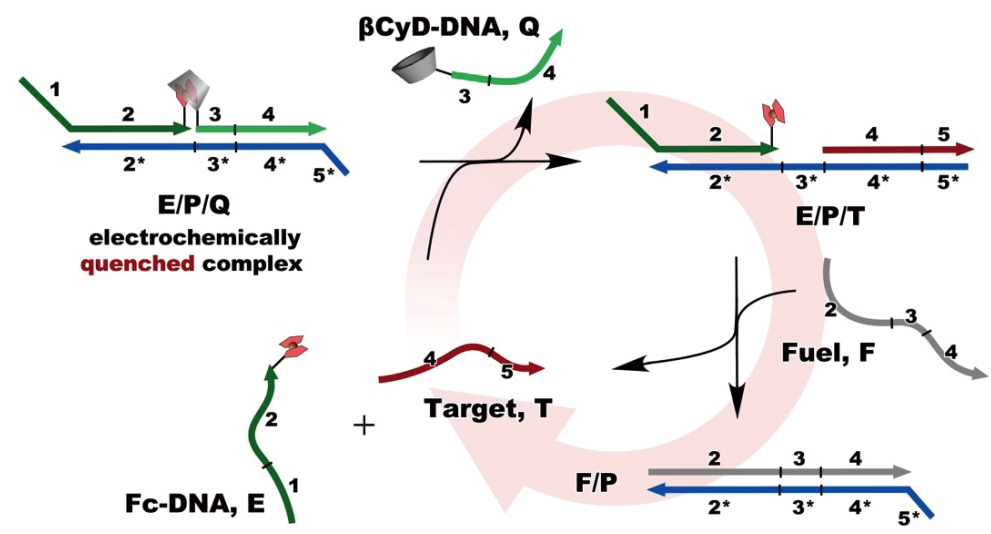

(b)

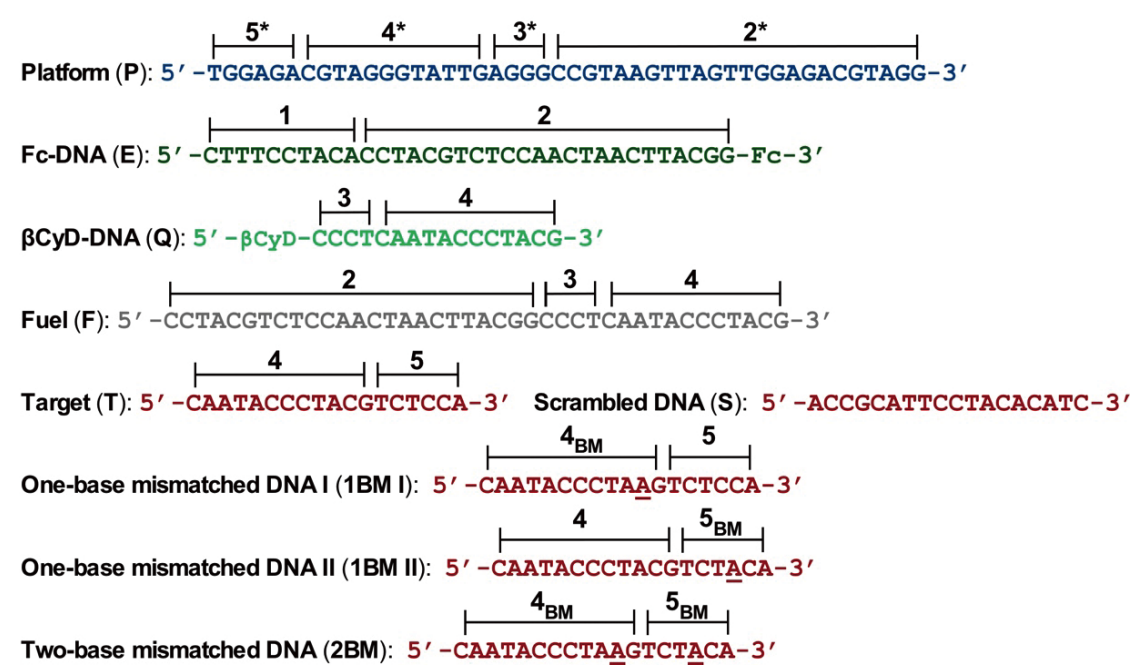

Fig. 1 (a) Electrochemical signal amplification based on catalytic dissociation of $\beta \mathrm{CyD} \supset \mathrm{Fc}$ inclusion complexes by entropy-driven DNA circuit. (b) Sequences of DNAs used in this study. ${ }^{9 c}$ Underlines in 1BM I, 1BM II, and 2BM indicate mismatched bases.

form $\mathbf{E} / \mathbf{P} / \mathbf{T}$. $\mathbf{F}$ then binds to $\mathbf{P}$ from the newly created accessible region, $3^{*}$, by replacing $\mathbf{T}$ and $\mathbf{E}$ to form a stable long duplex, $\mathbf{F} / \mathbf{P}$. $\mathbf{F}$ fuels the DNA circuit, and $\mathbf{T}$ is recycled as a catalyst for initiation of the next round. The dissociation of $\mathbf{Q}$ from the initial $\mathbf{E} / \mathbf{P} / \mathbf{Q}$ complex restores the electrochemical activity of $\mathrm{Fc}$ on $\mathbf{E}$. The released $\mathbf{E}$ is designed to be captured by a capture DNA (C) modified on the electrode through strand exchange to form the duplex $\mathbf{E} / \mathbf{C}$, in which $\mathrm{Fc}$ is close to the electrode. The capture of $\mathbf{E}$ therefore leads to the condensation of $\mathrm{Fc}$ on the electrode surface, which facilitates the electrochemical response of $\mathbf{E}$.

\section{Synthesis of conjugates}

DNA conjugates of $\mathbf{Q}$ and $\mathbf{E}$ were synthesized according to our previously reported method (Scheme S1, Supporting Information). ${ }^{22 a, 22 b}$ They were purified by reversed-phase highperformance liquid chromatography (RP-HPLC) (Fig. S1, Supporting Information) and identified by matrix-assisted laser desorption ionization-time-of-flight mass spectrometry (MALDI-TOF MS). Briefly, 5'-aminopropyl-linked DNA was conjugated with $\mathrm{N}$-succinimidyl 3-(2-pyridyldithio)propionate (SPDP) to form SPDP-DNA. $\beta$ CyD was introduced at a DNA end by thiol-disulfide exchange between SPDP-DNA and monothiolated $\beta$ CyD to obtain $\mathbf{Q}$. E was prepared by coupling
3 -aminohexyl-linked DNA with the $N$-hydroxysuccinimide active ester of ferrocenecarboxylic acid.

\section{Electrochemical measurements}

Electrochemical measurements were performed using an electrochemical analyzer (ALS 842B, BAS) with a conventional three-electrode system in a $10 \mathrm{mM}$ potassium phosphate buffer (pH 7.0) containing $500 \mathrm{mM} \mathrm{KCl}$. A glassy-carbon disk $(1.0 \mathrm{~mm} \phi)$ or gold disk $(3.0 \mathrm{~mm} \phi)$, platinum wire, and $\mathrm{Ag} / \mathrm{AgCl}$ (with $3.0 \mathrm{M} \mathrm{NaCl}$ ) were used as the working, auxiliary, and reference electrodes, respectively. Differential pulse voltammetry was performed by scanning from +0.2 to $+0.6 \mathrm{~V}$ with a $200 \mathrm{~ms}$ pulse period, a $25 \mathrm{mV}$ pulse amplitude, a $50 \mathrm{~ms}$ pulse width, and a $4 \mathrm{mV}$ potential increment.

\section{Fabrication of DNA-modified electrode}

A gold disk electrode was sequentially polished with a $6 \mu \mathrm{m}$ diamond slurry, a $1 \mu \mathrm{m}$ diamond slurry, and a $0.05 \mu \mathrm{m}$ alumina slurry (Maruto Instruments). The electrode was sonicated in water and blow dried with nitrogen. Then, $1 \mu \mathrm{M} \mathrm{C}(5 \mu \mathrm{L})$ prepared in a $1 \mathrm{M}$ potassium phosphate buffer $(\mathrm{pH} 7.0)$ containing $1 \mathrm{mM}$ tris(2-carboxyethyl)phosphate was placed on the electrode surface. The electrode was left for $2 \mathrm{~h}$ at $25^{\circ} \mathrm{C}$. After rinsing with water, and then nitrogen blow drying, $1 \mathrm{mM}$ 
(a)

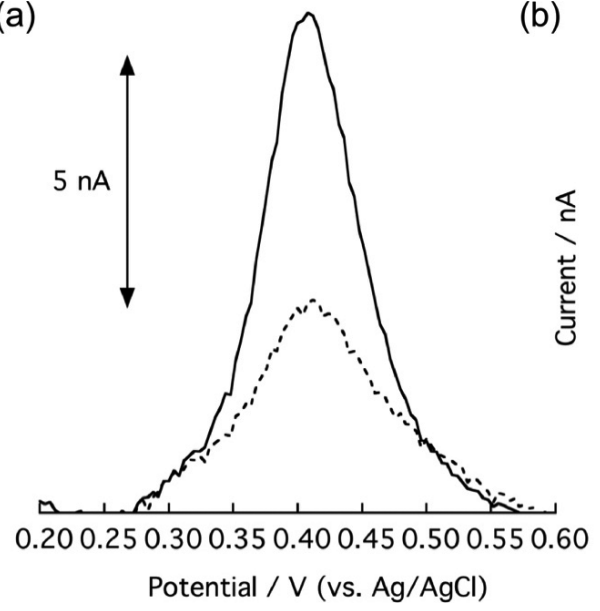

(b)

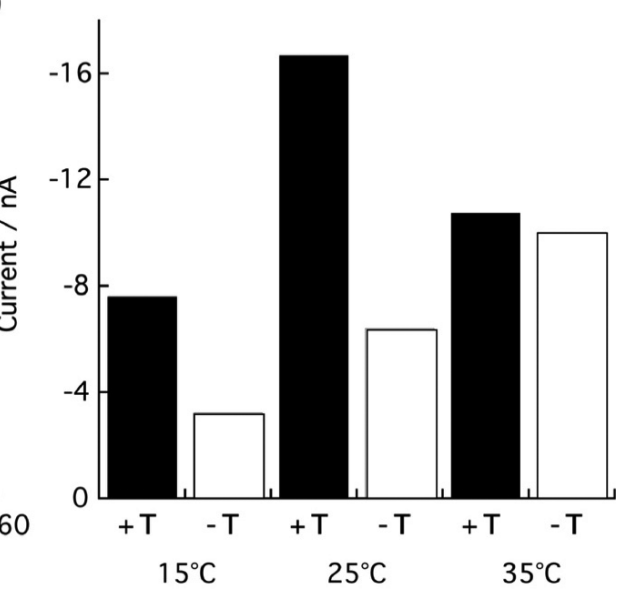

Fig. 2 (a) Differential pulse voltammograms of solution containing $40 \mu \mathrm{M} \mathrm{E} / \mathbf{P} / \mathbf{Q}$ and $44 \mu \mathrm{M} \mathrm{F}$ in presence of $4 \mu \mathrm{M} \mathbf{T}$ (solid curve) and absence of $\mathbf{T}$ (dashed curve). Measurements were performed in $10 \mathrm{mM}$ phosphate buffer ( $\mathrm{pH} 7.0$ ) containing $500 \mathrm{mM} \mathrm{KCl}$ at $25^{\circ} \mathrm{C}$ after incubation for $30 \mathrm{~min}$, with a glassy-carbon disk as the working electrode. (b) Peak currents of solutions incubated at 15, 25, and $35^{\circ} \mathrm{C}$ for $5 \mathrm{~h}$ in presence (filled bars) and absence (open bars) of $4 \mu \mathrm{M} \mathrm{T}$.

6-mercapto-1-hexanol solution $(5 \mu \mathrm{L})$ was placed on the electrode surface, and the electrode was left for $1 \mathrm{~h}$ at $25^{\circ} \mathrm{C}$. Finally, after rinsing with water and then nitrogen blow drying, $10 \mu \mathrm{M} \mathrm{M}(5 \mu \mathrm{L})$ prepared in $1 \mathrm{M}$ potassium phosphate buffer (pH 7.0) containing $500 \mathrm{mM} \mathrm{KCl}$ was placed on the electrode surface, and the electrode was left for $30 \mathrm{~min}$ at $25^{\circ} \mathrm{C}$ to form a C/M duplex. ${ }^{25}$ The surface density of DNA immobilized on the gold substrate was calculated from the amount of a bound redox marker, i.e., $\left[\mathrm{Ru}\left(\mathrm{NH}_{3}\right)_{6}\right]^{3+}(\mathrm{RuHeX})$, which was determined by chronocoulometry. ${ }^{26}$ The calculated value was $2.6 \times 10^{12}$ molecules $/ \mathrm{cm}^{2}$ (Fig. S2, Supporting Information).

\section{Results and Discussion}

The electrochemical responses of a DNA circuit with a glassycarbon electrode in the presence and absence of $\mathbf{T}$ are shown in Fig. 2. A peak derived from the oxidation of $\mathrm{Fc}$ was clearly observed at around $+0.41 \mathrm{~V}$ (vs. $\mathrm{Ag} / \mathrm{AgCl}$ ) (Fig. 2(a)) for a solution containing $\mathbf{E} / \mathbf{P} / \mathbf{Q}$ and $\mathbf{F}$ in the presence of $\mathbf{T}$. The signal observed in the absence of $\mathbf{T}$ was much lower than that in the presence of $\mathbf{T}$. As expected, the electrochemical signal from $\mathbf{E}$ was suppressed as a result of the formation of an inclusion complex between $\mathrm{Fc}$ and $\beta \mathrm{CyD}$ on the $\mathbf{E} / \mathbf{P} / \mathbf{Q}$ tandem ternary duplex. A smaller signal observed in the absence of $\mathbf{T}$ was due to an undesired strand exchange (leakage) judging from almost complete quenching of the electrochemical signal obtained in a previous study.22a Therefore, the reaction temperature was optimized by monitoring the differences between the peak currents obtained with and without T. As shown in Fig. 2(b), the highest value with $\mathbf{T}$, and the largest difference between the currents with and without $\mathbf{T}$, were observed at $25^{\circ} \mathrm{C}$. At a higher temperature, i.e., $35^{\circ} \mathrm{C}$, a lower value with $\mathbf{T}$ and a higher value without $\mathbf{T}$ were observed, probably because of a lower binding efficiency of $\mathbf{T}$ with $\mathbf{P}$ and an increase in leakage, respectively. At a lower temperature, i.e., $15^{\circ} \mathrm{C}$, although minimum leakage occurred without $\mathbf{T}$, the circuit did not run, even with $\mathbf{T}$, probably because the system was not supplied with enough thermal energy to overcome the activation energy barrier. Subsequent experiments were therefore performed at $25^{\circ} \mathrm{C}$

The time courses of the normalized peak currents $[=$ (peak currents with $\mathbf{T}$ ) - (peak currents without $\mathbf{T})$ ] were monitored with a bare glassy-carbon electrode in the presence of various amounts of $\mathbf{T}$ (Fig. 3(a)). The peak currents clearly increased with increasing time and the amount of $\mathbf{T}$ (Fig. 3(a), inset). A moderate increase, caused by leakage, was observed in the absence of $\mathbf{T}$ (data not shown). The turnover number (TON) of the catalytic cycle was determined by designating the peak current for $40 \mu \mathrm{M} \mathrm{E}$ at $25^{\circ} \mathrm{C}$ as the standard value (Fig. S3, Supporting Information). The TON was calculated as the ratio of the peak current to the standard current (peak current/ standard) divided by the equivalent ratio of $\mathbf{T}$ (catalyst). In the presence of $4 \mu \mathrm{M} \mathbf{T}$ ( 0.1 equiv) after incubation for $1 \mathrm{~h}$, the calculated TON was 1.9. The obtained TON was comparable to that of our previous study ( $\mathrm{TON}=2.1$ ) based on the catalytic formation of a luminescent lanthanide complex using an entropy-driven DNA circuit under comparable experimental conditions. ${ }^{20}$ The detection limit of this system was estimated to be $200 \mathrm{nM}$ (3 SD of the background noise).

The sequence fidelity of the system was evaluated by comparing the catalytic activities in the presence of 0.1 equiv of T and spurious targets (1BM I, 1BM II, 2BM, or S). 1BM I and 1BM II have a mismatched base at the starting point of the branch migration (the end of domain $4^{*}$ ) and at the middle of the toehold ( $5^{*}$ ) for the invasion of $\mathbf{T}$ into $\mathbf{E} / \mathbf{P} / \mathbf{Q}$ to displace $\mathbf{Q}$, respectively. The time courses of the normalized peak currents are shown in Fig. 3(b). The currents with 1BM I and 1BM II were smaller than that with $\mathbf{T}$. This indicates that the mismatched bases suppressed the catalytic reactions. In the cases of $\mathbf{2 B M}$ and $\mathbf{S}$, which have two mismatched bases at domains $4^{*}$ and $5^{*}$ and a scrambled sequence of $\mathbf{T}$, respectively, the catalytic activities were very low and much smaller peak currents were obtained. The suppression factors were calculated as the initial rate of the reaction with $\mathbf{T}$ divided by the rates with the mismatched targets, according to the following equation:

Suppression factor $=$ (normalized peak current with $\mathbf{T}$ at $30 \mathrm{~min}) /($ normalized peak current with spurious catalyst at $30 \mathrm{~min})$.

The suppression factors for the spurious catalysts 1BM I, 

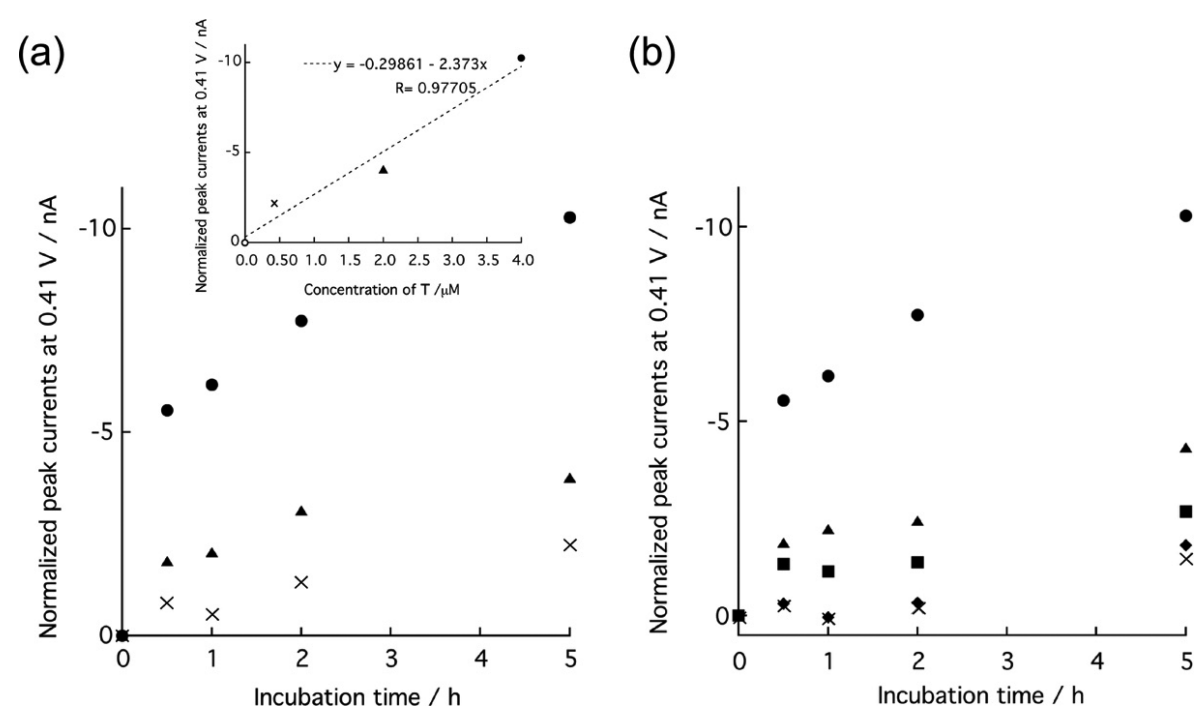

Fig. 3 (a) Time courses of normalized peak currents [(peak currents with $\mathbf{T}$ ) - (peak currents without $\mathbf{T})$ ] of solution containing $40 \mu \mathrm{M} \mathrm{E} / \mathbf{P} / \mathbf{Q}$ and $44 \mu \mathrm{M} \mathrm{F}$ at $0.41 \mathrm{~V}$ in presence of various amounts of $\mathbf{T}$ ( $0.4 \mu \mathrm{M}$ : cross; $2 \mu \mathrm{M}$ : triangle; $4 \mu \mathrm{M}$ : filled circle). Inset: concentration of $\mathbf{T}$ vs peak current plots for $5 \mathrm{~h}$ incubation. (b) Time courses of normalized peak currents of solution containing $40 \mu \mathrm{M} \mathrm{E} / \mathbf{P} / \mathbf{Q}$ and $44 \mu \mathrm{M} \mathrm{F}$ in presence of various targets at concentration $4 \mu \mathrm{M}$ (T: circle; 1BM I: square; 1BM II: triangle; 2BM: diamond; $\mathbf{S}$ : cross). Measurements were performed in $10 \mathrm{mM}$ phosphate buffer ( $\mathrm{pH}$ 7.0) containing $500 \mathrm{mM} \mathrm{KCl}$ at $25^{\circ} \mathrm{C}$ with a glassy-carbon disk as the working electrode.

(a)

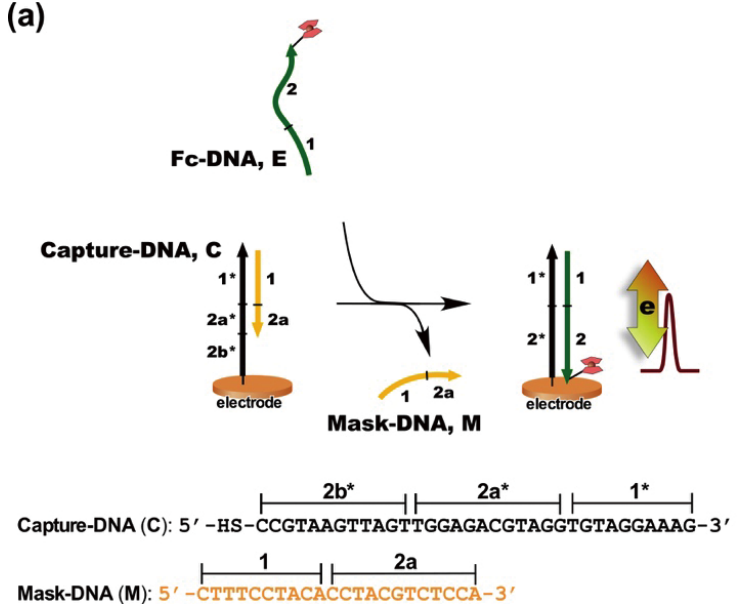

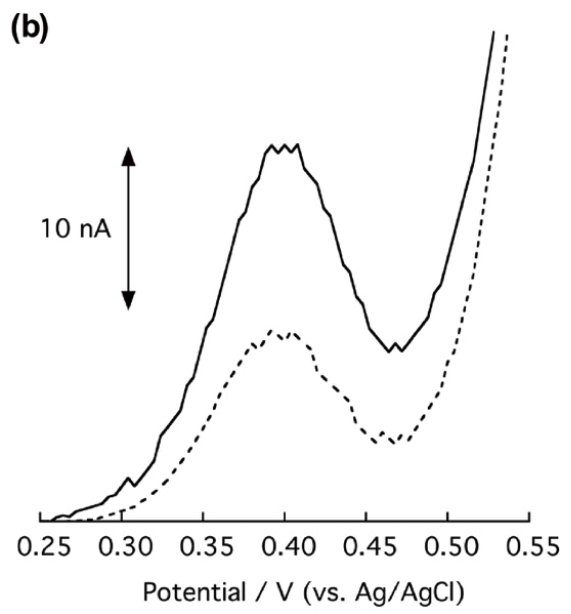

Fig. 4 (a) Entrapment of $\mathbf{E}$ on gold electrode surface through toehold-mediated strand exchange. (b) Differential pulse voltammograms of solution containing $10 \mu \mathrm{M} \mathrm{E} / \mathbf{P} / \mathbf{Q}$ and $11 \mu \mathrm{M} \mathrm{F}$ in presence of $1 \mu \mathrm{M} \mathbf{T}$ using a bare gold disk (dashed curve) or gold disk modified with $\mathbf{M} / \mathbf{C}$ duplex (solid curve) as the working electrode. Measurements were performed in $10 \mathrm{mM}$ phosphate buffer ( $\mathrm{pH} 7.0)$ containing $500 \mathrm{mM} \mathrm{KCl}$ at $25^{\circ} \mathrm{C}$ after incubation for $5 \mathrm{~h}$.

1BM II, 2BM, and $\mathbf{S}$ were 3.8, 2.4, 5.7, and 7.0, respectively. These results indicate that the mismatched bases hindered binding of the spurious catalysts and prevented precise execution of the programmed amplification cycle.

Finally, we tried to entrap the released $\mathbf{E}$ to enhance the sensitivity, as shown in Fig. 4(a). A modification of the gold electrode with a duplex consisting of $\mathbf{C}$ and $\mathbf{M}$, in which $\mathbf{M}$ prevents a direct strand exchange of $\mathbf{E} / \mathbf{P} / \mathbf{Q}$ with $\mathbf{C}$ to form $\mathbf{E} / \mathbf{C}$ without the participation of $\mathbf{T}$, doubled the peak current compared with that of the system without any $\mathbf{M} / \mathbf{C}$ modification of the electrode (Fig. 4(b)). This is the result of accelerating the electrochemical reaction, which is caused by a selective entrapment and concentration of $\mathrm{Fc}$ on the electrode surface.

\section{Conclusions}

We successfully detected target DNA in a homogeneous solution. The electrochemical signal was successfully modulated by the formation and dissociation of an inclusion complex consisting of $\mathrm{Fc}$ and $\beta \mathrm{CyD}$. The electrochemical response was amplified by combining with an entropy-driven DNA circuit. 
In addition to the detection of target nucleic acids, including particular genes of interest, mRNA, and miRNA, ${ }^{27}$ the system can be used for electrochemical sensing of other molecules that replace a strand from a tandem duplex carrying a cognate nucleic acid aptamer. ${ }^{28}$

\section{Acknowledgements}

This research was supported by a grant-in-aid for Scientific Research (B) (No. 20H02769 to T. I.) from the Ministry of Education, Culture, Sports, Science, and Technology, Japan. We thank Helen McPherson, PhD, from Edanz Group (https:// en-author-services.edanzgroup.com/ac) for editing a draft of this manuscript. The authors would like to thank Dr. Shigeori Takenaka and Dr. Shinobu Sato of Kyushu Institute of Technology for their helpful advice on the chronocoulometric measurements.

\section{Supporting Information}

Synthetic scheme for the conjugates. RP-HPLC chromatograms for the isolation of $\mathbf{F}$ and $\mathbf{Q}$ after each synthesis. Chronocoulometric measurements. Differential pulse voltammograms of solution containing $40 \mu \mathrm{M} \mathrm{E}$ at $25^{\circ} \mathrm{C}$. These materials are available free of charge on the Web at http://www.jsac.or.jp/ analsci/.

\section{References}

1. W. Engelen, L. H. H. Meijer, B. Somers, T. F. A. de Greef, and M. Merkx, Nat. Commun., 2017, 8, 14473.

2. J.-S. Shin, J. Am. Chem. Soc., 2004, 126, 10834.

3. C. Jung, P. B. Allen, and A. D. Ellington, Nat. Nanotechnol., 2016, 11, 157.

4. T. Song, S. Shah, H. Bui, S. Garg, A. Eshra, D. Fu, M. Yang, R. Mokhtar, and J. Reif, J. Am. Chem. Soc., 2019, 141, 16539.

5. H. Liang, S. Chen, P. Li, L. Wang, J. Li, J. Li, H.-H. Yang, and W. Tan, J. Am. Chem. Soc., 2018, 140, 4186.

6. K. T. Kim, S. Angerani, D. Chang, and N. Winssinger, $J$. Am. Chem. Soc., 2019, 141, 16288.

7. (a) P. M. Dirks and N. A. Pierce, Proc. Natl. Acad. Sci. U. S. A., 2004, 101, 15275. (b) G. Zhu, J. Zheng, E. Song, M. Donovan, K. Zhang, and W. Tan, Proc. Natl. Acad. Sci. U. S. A., 2013, 110, 7998. (c) F. Xuan and I.-M. Hsing, J. Am. Chem. Soc., 2014, 136, 9810.

8. (a) P. Yin, H. M. T. Choi, C. R. Calvert, and N. A. Pierce, Nature, 2008, 451, 318. (b) Y. S. Jiang, B. Li, J. N. Miligan, S. Bhadra, and A. D. Ellington, J. Am. Chem. Soc., 2013, 135, 7430. (c) Y. Lv, R. Peng, X. Zhang, and W. Tan, Chem. Commun., 2016, 52, 1413. (d) S. Bi, B. Xiu, J. Ye, and Y. Dong, ACS Appl. Mater. Interfaces, 2015, 7, 23310.

9. (a) D. Y. Zhang, A. J. Turberfield, B. Yurke, and E. Winfree, Science, 2007, 318, 1121. (b) R. Bar-Ziv, Science, 2007,
318, 1078. (c) D. Y. Zhang and E. Winfree, Nucl. Acids Res., 2010, 38, 4182. (d) Y. Lv, L. Cui, R. Peng, Z. Zhao, L. Qiu, H. Chen, C. Jin, X.-B. Zhang, and W. Tan, Anal. Chem., 2015, 87, 11714.

10. H. M. T. Choi, J. Y. Chang, L. A. Trinh, J. E. Padilla, S. E. Fraser, and N. A. Pierce, Nat. Biotechnol., 2010, 28, 1208.

11. R. Lin, Q. Feng, P. Li, P. Zhou, R. Wang, Z. Liu, Z. Wang, X. Qi, N. Tang, F. Shao, and M. Luo, Nat. Methods, 2018, 15,275

12. B. Li, A. D. Ellington, and X. Chen, Nucl. Acids Res., 2011, 39, e110.

13. Q. Wei, J. Huang, J. Li, J. Wang, X. Yang, J. Liu, and K. Wang, Chem. Sci., 2018, 9, 7802.

14. D. Han, Z. Zhu, C. Wu, L. Peng, L. Zhou, B. Gulbakan, G. Zhu, K. R. Williams, and W. Tan, J. Am. Chem. Soc., 2012, 134, 20797.

15. Y. Lv, L. Cui, R. Peng, Z. Zhao, L. Qiu, H. Chen, C. Jin, X.-B. Zhang, and W. Tan, Anal. Chem., 2015, 87, 11714.

16. S. Angerani and N. Winssinger, J. Am. Chem. Soc., 2020, $142,12333$.

17. X. Chang, C. Zhang, C. Lv., Y. Sun, M. Zhang, Y. Zhao, L. Yang, D. Han, and W. Tan, J. Am. Chem. Soc., 2019, 141 , 12738.

18. Y. Kitamura, T. Miyahata, H. Matsuura, K. Hatakeyama, T. Taniguchi, M. Koinuma, Y. Matsumoto, and T. Ihara, Chem. Lett., 2015, 44, 1353.

19. Y. Kitamura, A. Nozaki, R. Ozaki, Y. Katsuda, and T. Ihara, ACS Appl. Bio Mater., 2019, 2, 2988.

20. Y. Kitamura, Y. Azuma, Y. Katsuda, and T. Ihara, Chem. Commun., 2020, 56, 3863.

21. (a) Y. Kitamura, T. Ihara, Y. Tsujimura, Y. Osawa, D. Sasahara, M. Yamamoto, K. Okada, M. Tazaki, and A. Jyo, J. Inorg. Biochem., 2008, 102, 1921. (b) Y. Kitamura, S. Yamamoto, Y. Osawa, H. Matsuura, and T. Ihara, Chem. Commun., 2013, 49, 285.

22. (a) T. Ihara, T. Wasano, R. Nakatake, P. Arslan, A. Futamura, and A. Jyo, Chem. Commun., 2011, 47, 12388. (b) Y. Kitamura, K. Mishio, P. Arslan, B. Ikeda, C. Imoto, Y. Katsuda, and T. Ihara, Anal. Sci., 2020, 36, 959. (c) A. Futamura, A. Uemura, T. Imoto, Y. Kitamura, H. Matsuura, C.-H. Wang, Y. Sato, N. Teramae, S. Nishizawa, and T. Ihara, Chem. Eur. J., 2013, 19, 10526.

23. (a) T. Ihara, T. Fujii, M. Mukae, Y. Kitamura, and A. Jyo, J. Am. Chem. Soc., 2004, 126, 8880. (b) M. Mukae, T. Ihara, M. Tabara, and A. Jyo, Org. Biomol. Chem., 2009, 7, 1349. (c) P. Arslan, A. Jyo, and T. Ihara, Org. Biomol. Chem., 2010, 8, 4843.

24. Y. Kitamura, T. Ihara, K. Okada, Y. Tsujimura, Y. Shirasaka, M. Tazaki, and A. Jyo, Chem. Commun., 2005, 4523.

25. T. M. Herne and M. J. Tarlov, J. Am. Chem. Soc., 1997, $119,8916$.

26. A. B. Steel, T. M. Herne, and M. J. Tarlov, Anal. Chem., 1998, 70, 4670.

27. K. Zhang, K. Wang, X. Zhu, and M. Xie, Anal. Chim. Acta, 2017, 949, 53.

28. D. Li, X. Li, B. Shen, P. Li, Y. Chen, S. Ding, and W. Chen, Anal. Chim. Acta, 2019, 1092, 102. 